\title{
PROGRAMA INSTITUCIONAL DE BOLSA DE INICIAÇÃO A DOCÊNCIA-PIBID E A FORMAÇÃO DOCENTE.
}

\author{
Artur Rodrigues ${ }^{1}$ \\ Maellem llibio Da Silva ${ }^{2}$ \\ Mainara Joaquim Mota $^{3}$ \\ Renato Porto De Borba ${ }^{4}$ \\ Vânia Vitorio ${ }^{5}$
}

\section{INTRODUÇÃO}

O tema escolhido para este estudo é Programa Institucional de Bolsa de Iniciação a Docência-PIBID e a Formação Docente. Busco com a pesquisa analisar quais as principais contribuições do programa para a formação dos acadêmicos envolvidos, do curso de licenciatura em Educação Física, da Universidade do Extremo Sul Catarinense - UNESC.

Optei por esse tema, por fazer parte do PIBID e perceber a influência do programa para os acadêmicos do curso de licenciatura em Educação Física da UNESC. Justifica-se este projeto pela necessidade de novas evidências científicas para formação de professores.

O objetivo geral da pesquisa é analisar a contribuição do PIBID na formação acadêmica, e os objetivos específicos: explicitar a estrutura do Programa Institucional de Bolsa de Iniciação à Docência- (PIBID), detalhar o subprojeto do curso de licenciatura em educação física e sua articulação teórica prática na formação acadêmica.

O trabalho intenciona responder sobre qual a contribuição do PIBID para a formação dos acadêmicos em licenciatura em educação física?

A pesquisa será realizada por meio de questionário envolvendo os acadêmicos bolsistas do subprojeto de Educação Física que participam desde o inicio do programa até a presente data, ou seja, (2014- 2015). O Total previsto de participantes foi de 21 bolsistas, mas teve com a participação de 10. A pesquisadora fez uma conversa com os bolsistas entregando o termo de consentimento e esclarecendo sobre o questionário que foi encaminhado via e - mail, para ser preenchido e devolvido no período máximo de cinco dias. 


\section{SOBRE O PIBID: ESTRUTURA E PROPOSTA}

Segundo Brasil (2007) o Programa Institucional de Iniciação a Docência (PIBID), foi inserido a partir da Portaria Normativa n 38, de 12 de dezembro de 2007, por meio de um acordo entre o Ministério da Educação, por intervenção da Secretaria de Educação Superior, para melhorar a iniciação à docência de estudantes das instituições.

O Programa de Iniciação à Docência atenderá a formação de docentes para atuar em todas as áreas de ensino e tem como objetivos de acordo com Brasil (2007, p. 39).

\footnotetext{
I Incentivar a formação de professores para a educação básica, especialmente para o ensino médio;

II - valorizar o magistério, incentivando os estudantes que optam pela carreira docente;

III - promover a melhoria da qualidade da educação básica;

IV - promover a articulação integrada da educação superior do sistema federal com a educação básica do sistema público, em proveito de uma sólida formação docente inicial;

$\mathrm{V}$ - elevar a qualidade das ações acadêmicas voltadas à formação inicial de professores nos cursos de licenciaturas das instituições de educação superior.
}

O programa fornece bolsas de estudos mensais de iniciação à docência aos acadêmicos das licenciaturas no valor de quatrocentos reais, bolsas de supervisão aos professores docentes nas escolas da rede pública no valor de setecentos e sessenta e cinco reais e bolsas de coordenação de subprojetos no valor de mil e quatrocentos reais.

As despesas do PIBID são pagas anualmente e registradas ao Ministério da Educação, a CAPES e ao FNDE.

O programa PIBID é em nível nacional e constam subprojetos do programa por todo o país. Um destes polos está localizado na UNESC, na cidade de Criciúma Santa Catarina. Que abrange o espaço territorial de três grandes microrregiões: Associação dos Municípios da Região Carbonífera, Associação dos Municípios do Extremo Sul Catarinense e Associação de Municípios da Região de Laguna. Atendendo alunos de toda esta esfera e também alunos de outros estados e países. 
De acordo com a Universidade do Extremo Sul Catarinense (2013), Os cursos de licenciatura da universidade existem, em sua maior parte, há mais de 40 anos. Portando é para os cursos de licenciaturas que o programa do PIBID esta direcionado. Na UNESC o programa PIBID é constituído pelos cursos de Educação física, Artes Visuais que atende 25 acadêmicos, 3 professores supervisores, e 2 coordenadores de área. O curso de Biologia contempla 25 acadêmicos, 3 professores supervisores, e 2 coordenadores de área. O curso de Geografia são 15 acadêmicos, 2 professores supervisores e 1 coordenador de área. O curso de Historia contém 25 acadêmicos, 3 professores supervisores, e 2 coordenadores de área. $\mathrm{O}$ curso de Letras atende 15 acadêmicos, 2 professores supervisores, e 1 coordenador de área. $O$ curso de Matemática inclui 25 acadêmicos, 3 professores supervisores, e 2 coordenadores de área. Pedagogia são 40 acadêmicos, 4 professores supervisores, e 2 coordenadores de área. A Universidade possui também o Subprojeto Interdisciplinar que contempla os cursos de Artes Plásticas e Visuais, História, Letras - Português, Pedagogia. São25 acadêmicos3 bolsas de supervisão e 2 Bolsas de coordenação de área. Os cursos de Artes Visuais, Letras, Ciências Biológicas, Matemática e Pedagogia, participam desde 2012, o restante a partir do edital de 2013 que iniciou em 2014.

O curso de Educação Física contempla 45 acadêmicos, 6 professores supervisores e 3 coordenadores de área, sendo que é o subprojeto que possui a maior quantidade de acadêmicos, coordenadores e professores supervisores envolvidos. Este dado se justifica por ser o maior curso de licenciatura em alunos matriculados na Universidade.

De acordo com UNESC (2013) o PIBID tem o propósito de fortalecer a formação inicial dos licenciados, contribuindo para a prática de suas aulas, reflexões das experiências e adquirindo mais conhecimento teórico através dos estudos propostos pelos subprojetos. Os estudos teóricos devem ir ao encontro das bases teóricas das propostas pedagógicas das escolas envolvidas no projeto, sendo que a da rede estadual e municipal tem por base a teoria de aprendizagem históricocultural.

As discussões teóricas partindo das orientações do Projeto da UNESC e do PPC do curso se direcionaram para análise do Projeto Político Pedagógico - PPP das escolas envolvidas no subprojeto de Educação Física que são da rede pública 
estadual de Santa Catarina e Municipal de Criciúma. Para UNESC (2013) os estudos devem partir da:

Análise da Proposta Curricular de Santa Catarina, da Proposta Curricular doMunicípio de Criciúma, do Projeto Político Pedagógico da Escola e do Planode Ensino do Professor. Toda a reflexão pedagógica consequente deve se iniciar com o estudo meticuloso dos documentos oficiais norteadores da prática pedagógica. Neste sentido, pretende-se organizar a leitura conjunta dos documentos oficiais, procurando esclarecer os conceitos e compreender os aspectos centrais das propostas. (UNESC, 2013, p 13).

O programa intenciona proporcionar aos bolsistas a aproximação com o espaço escolar e subsidiar lhes possibilidades concretas da leitura da realidade e do meio vivido dos alunos, para que então possam intervir nesta realidade de forma mais qualificada. Esta intervenção é realizada pelos bolsistas com o acompanhamento dos professores, coordenadores e supervisores a partir de leitura e discussão de textos, artigos, livros, teses que tem por base a teoria de aprendizagem defendida pela rede.

De acordo com UNESC (2013) através dos estudos teóricos e práticos, deseja qualificar a formação dos bolsistas participantes do PIBID.

\section{O SUBPROJETO DA EDUCAÇÃO FíSICA}

O subprojeto da Educação Física iniciou no dia 29 de março de 2014 com a leitura do termo de compromisso e do projeto PIBID da UNESC entre todos os bolsistas, coordenadores e professores supervisores.

A organização do subprojeto PIBID de Educação Física da Universidade do Extremo Sul Catarinense - UNESC se dá em encontros presenciais quinzenais aos sábados e semanalmente nas escolas. Os sábados em que não há encontro são direcionados aos estudos propostos pelos coordenadores que envolvem textos, artigos, dissertações, teses, livros com a elaboração de resenhas e de material para debate. Deste modo cumprindo quatro horas presenciais na Universidade, quatro para leitura e elaboração de materiais e quatro horas na escola, onde são realizadas observações, coatuação e atuação nas aulas de Educação Física, acompanhadas pelos professores supervisores, em um total de oito horas semanais. Toda ação na escola é estudada, pensada, planejada e discutida pelos professores coordenadores do subprojeto em conjunto com os supervisores e acadêmicos. 
A observação, coatuação e atuação são estendidas por todo o ano letivo. Desta forma, considera-se que através do PIBID o acadêmico bolsista do subprojeto de Educação Física da UNESC, tem a possibilidade de se reconhecer como futuro professor, fazer a leitura da realidade da escola e da sua prática para compreensão e interação no espaço escolar. Vivenciando diversas situações do dia a dia da escola com intervenções em consonância com o Projeto Pedagógico do Curso de Educação Física.

As discussões teóricas são mediadas pelos coordenadores nos encontros de sábado e estão articuladas ao Projeto Político do Curso de educação física que se posiciona para as teorias críticas da educação, que intenciona formar licenciados que se apropriem do conhecimento da cultura corporal de movimento, enquanto produto do seu meio sócio-histórico e na sua socialização, contribua para desenvolver as possibilidades de transformação social.

Esse profissional de educação física, com consciência de sua capacidade de transformação da realidade, deve ser comprometido com o seu próprio processo formativo, compreendendo-se como agente de sua história, da história social, assumindo papel de educar, tematizando a cultura corporal de movimento como o conhecimento da Educação Física. (PROJETO PEDAGÓGICO DO CURSO DE EDUCAÇÃO FÍSICA- UNESC, 2010, p. 13).

As propostas críticas apontadas no PPC do curso, em especial a proposta pedagógica crítico superadora tem como base teórica a teoria de aprendizagem histórico cultural, mesma base das propostas da rede pública estadual e municipal das escolas envolvidas no programa.Assim o Coletivo de Autores (1992, pg. 62) menciona,

A metodologia na perspectiva critica Superadora implica num processo que acentue, na dinâmica da sala de aula, a intenção pratica do aluno para aprender a realidade. Por isso, entendemos a aula como um espaço intencionalmente organizado para possibilitar a direção da apreensão, pelo aluno, do conhecimento especifico da Educação Física e dos diversos aspectos das suas práticas na realidade social.

Contudo é importante frisar a importância da direção epistemológica e ontológica dos estudos para orientar a análise e intervenção dos bolsistas no espaço escolar, sem o qual não obtém condições suficientes para sair do senso comum e avançar no debate sobre formação e educação.

A grande conquista do PIBID da Universidade do Extremo Sul Catarinense do subprojeto da educação física, talvez seja se constituir como base 
para reflexões da realidade da escola, de forma mais ampla e mais profunda, a partir de um referencial teórico consistente intervindo no processo de formação dos acadêmicos participantes do PIBID e dos professores envolvidos.

\title{
OS ESTUDOS NO SUBPROJETO DA EDUCAÇÃO FíSICA
}

No subprojeto de Educação Física da UNESC os estudos foram organizados a partir da base teórica da Proposta Curricular de Santa Catarina e a Proposta Curricular do Município de Criciúma. Ambas apontam a Concepção de aprendizagem histórico cultural formulada por Vigotsky.

A teoria histórico cultural é um estudo na área da psicologia que trata de compreender como se da as elaborações mentais para aprendizagem. A teoria defende que o ser humano aprende e se constrói historicamente e culturalmente, e é na relação com o outro que ele vai fazendo as elaborações mentais que o torna humano. É nesse processo de formação histórica, que o ser humano se desenvolve.

\begin{abstract}
O que Vigotsky procurou foi uma abordagem abrangente que possibilitasse a descrição e a explicação das funções psicológicas superiores, em termos aceitáveis para as ciências naturais. Para Vigotsky, essa explicação tinha o significado de uma grande tarefa. Ela deveria incluir a identificação dos mecanismos cerebrais subjacentes à determinada função; a explicação detalhada de sua história ao longo do desenvolvimento, com o objetivo de estabelecer as relações entre formas simples e complexas daquilo que aparentava ser o mesmo comportamento; e de forma importante, deveria incluir a especificação do contexto social em que se deu o desenvolvimento do comportamento. (VIGOTSKY, 2010, p 23-24).
\end{abstract}

Para melhor compreensão do desenvolvimento das funções psicológicas superiores responsáveis para formação da atividade humana nos reportaram a Davidov que a partir da teoria da atividade de Leontiev indica que os elementos principais da atividade humana estruturam a atividade de ensino e da aprendizagem.

Os componentes da construção da atividade humana para Davidov (1999) são os mesmos componentes da atividade de estudo. Estes elevam o desenvolvimento das funções psicológicas superiores, condição necessária para levar o aluno a pensar teoricamente.

Segundo Davidov (1999) o ensino deve se preocupar em colocar o aluno em atividade de estudo na escola.

A organização de atividade de estudo consiste em que o professor embasado na necessidade e disposição dos alunos de dominar os conhecimentos 
teóricos, saiba colocar para eles um determinado material de estudo que busque no aluno entusiasmo e vontade de aprender.

Para Davidov (1999) para o aluno pensar teoricamente ele deve entrar em atividade de estudo, ou seja, a atividade que o permita fazer a interligação entre o essencial-geral e o particular do objeto a ser estudado.

Em contribuição a este debate buscou-se em Frizzo (2013) reflexões sobre o objeto de estudo da educação física.

Frizzo (2013) destaca três perspectivas que preponderam no debate a cerca do geral da educação física: as idealistas (o movimento humano, a cultura corporal do movimento), e materialistas (cultura corporal).

Para Frizzo (2013)as elaborações idealistas se referem à dualidade entre corpo emente, sujeito e objeto, tempo e espaço presentes na proposição do movimento humano de Manuel Sérgio (1987) e na centralidade do papel da linguagem, da subjetividade e dos discursos como constituintes da realidade defendidas por Betti (2007) e dos estudos de Neira e Nunes (2011).

Estas perspectivas tratam do movimento humano descolado do contexto social, desconsiderando-o. Como se o corpo pudesse ser isolado do ser humano e também da historia e da cultura que está inserido.

Em contraposição a estas perspectivas, estáà cultura corporal uma perspectiva materialista que se reporta para a leiturae compreensão da realidade.

De acordo com Frizzo (2013) a cultura corporal como objeto de estudo da Educação Física aborda princípios científicos e filosóficos materialistas onde a atividade humana é o embasamento da fabricação desta parte da cultura, e as suas manifestações são idealizadas através das suas significações socialmente estabelecidas e de seu significado de período histórico. Entretanto a cultura corporal parte da classe trabalho enquanto atividade humana que possui produtividade de suas condições objetivas de vivência, ou seja, a cultura é obra da atividade do ser humano e das relações que se constitui com os outros seres humanos.

A aula tendo como plano de fundo um projeto histórico com a finalidade de contribuir para a leitura da realidade e responder aos interesses da classe trabalhadora deve levar o aluno a atividade de estudo tornando capaz de pensar na totalidade dos problemas da sociedade e com condições de apresentar soluções. 
Para Davidov (1999) para que o aluno chegue à síntese, ou seja, ao pensamento teórico que é a capacidade de elaborar conceitos teóricos oriundos de abstrações, generalizações,é necessário à organização e sistematizada da aula.

Neste sentido a proposta crítico-superadora do Coletivo de Autores (1992) que tem a cultura corporal como seu objeto de estudoindica como o conhecimento de seus temas: jogo, esporte, luta, dança e ginástica que deve ser tratado.

Para o Coletivo de Autores (1992) o trato com o conhecimento deve seguir princípios de seleção, organização e sistematização dos conteúdos sendo que estes devem refletir sua direção epistemológica. Essa direção deve se manifestar no currículo escolar e estar vinculada ao Projeto político pedagógico da escola.

Com preocupação na atividade pedagógica da educação física Nascimento (2014) faz em sua tese proposições sobre o desenvolvimento das atividades da cultura corporal nas aulas de Educação Física e seus objetos de ensino.

Nascimento (2014) investiga as condições indispensáveis para o surgimento das atividades da cultura corporal e as relações essenciais que as constituem. Dessa investigação aponta duas sínteses principais: A primeira trata às dimensões simultaneamente humanizadora e alienadora das atividades da cultura corporal, ou seja, dimensões que se encontra resumidas no fenômeno esporte. A segunda síntese trata das proposições das relações essenciais da cultura corporal. Esta consiste na criação de uma imagem artística com as ações corporais, no controle da ação corporal do outro e no domínio da própria ação corporal.

Essas relações, sistematizadas em seus aspectos gerais, se constituem nos objetos de ensino da Educação Física, que formam critério pedagógico central para determinar os conteúdos eorganizar o ensino dessa disciplina na perspectiva histórico-cultural.

A partir destes estudos realizados no subprojeto de Educação Física da UNESC, foi elaborada a pesquisa e que passaremos apresentar os dados.

\section{ANÁLISE DE DADOS}

A pesquisa foi realizada por meio de questionário envolvendo os acadêmicos bolsistas do subprojeto de Educação Física que participam desde o 
inicio do programa até a presente data, ou seja, (2014- 2015). O Total previsto de participantes foi de 21 bolsistas, mas se efetivou com a participação de 10 bolsistas.

A análise da pesquisa é qualitativa e envolve a totalidade das respostas objetivas e os aspectos centrais das respostas justificadas buscando a reflexão junto ao referencial teórico.

Primeiramente buscam-se conhecer aspectos de caráter interpessoal sobre a formação dos bolsistas e posteriormente aspectos relacionados ao programa PIBID.

A primeira questão se refere ao que influenciou a opção dos bolsistas pelo curso de licenciatura em educação física?

Nessa perspectiva oito dos bolsistas apontaram que estavam preocupados com a qualidade da Educação Física escolar.

O curso de licenciatura em Educação Física da UNESC possui uma história de qualidade, que se expressa na sociedade que entendemos promover a procura pelo curso. Não se pode desconsiderar que a preocupação com a qualidade da Educação Física escolar, pode estar relacionada à qualidade do ensino da Educação Física que esses bolsistas tiveram em sua vida escolar e querem dar continuidade, ou na sua insuficiência que desperta a vontade de querer melhorar.

Outro questionamento foi que ao ingressar no PIBID, que atividades esperavam realizar?

Sete dos bolsistas ao entrar no PIBID estavam preocupados com a qualificação profissional. E os demais achavam que iriam observar a prática do professor na escola.

Deste modo analisa-se que os bolsistas ao ingressarem no programa buscavam ainda mais conhecimento para se preparem e qualificar profissionalmente para serem futuros professores.

Quando questionados sobre qual a contribuição do PIBID para a formação docente dos bolsistas do subprojeto de Educação Física da UNESC?

Os dez bolsitas afirmam que a contribuição do PIBID é positiva, e apontam como justificativa o debate aprofundado das obras, a atuação e o planejamento das aulas, que são extremamente importantes para a formação.

Acrescentam ainda a participação em eventos, que contribui muito na formação e aproximação com a realidade da escola que amplia o tempo para além do estágio. Entretanto todos os textos estudados são fundamentais, pois os bolsistas 
estudam na Universidade as bases teóricas e podem ter contato com a escola, não esperando somente pelo estágio. Possibilita também ao bolsista uma bolsa para que ele possa aprofundar o conhecimento cientifico além do que o curso oferece.

\begin{abstract}
Numa perspectiva dialética, os conteúdos teriam que ser apresentados aos alunos a partir do princípio da simultaneidade, /explicitando a relação que mantêm entre si para desenvolver a compreensão de que são dados da realidade que não podem ser pensados nem explicados isoladamente. ' Nessa perspectiva o que mudaria de uma unidade para outra seria a amplitude das referências sobre cada dado, isso porque "o conhecimento não é pensado por etapas. Ele é construído no pensamento de forma espiralada e vai se ampliando" (Varjal, 1991, p. 35 2007, apud COLETIVO DE AUTORES, 1992, p.21).
\end{abstract}

Esse conhecimento que o subprojeto possibilita é de grande importância, pois oferece aos bolsistas a compreensão do objeto de estudo da educação física, a proposta crítico superadora e como ensinar cada um dos conteúdos da cultura corporal, assim como outros conhecimentos teóricos e práticos com uma maior amplitude.

Outro questionamento foi se o PIBID contribuiu para a prática docente nas co-atuações e atuações dos acadêmicos nas escolas participantes?

Os dez bolsistas concordam que o PIBID contribui na prática docente através das co-atuações e atuações. E apontam como justificativa que contribuiu dando um embasamento teórico para podermos elaborar os planos, e para colocálos em prática em nossas atuações nas escolas. Posteriormente para vivenciar a realidade da escola.

Percebe - se que o PIBID contribui com os bolsistas durante as coatuações e atuações, pois eles se reconhecemcomo futuros professores.

A última questão foi se o PIBID contribuiu para a formação docente dos acadêmicos?

Todos os bolsistas afirmam que contribui para a formação docente, através do conhecimento adquirido no programa, pois permite diversas experiências que contribui na prática pedagógica.

Para o Bolsista 08 possibilita experiências que contribuem na prática pedagógica docente dos acadêmicos que trabalham em escolas e nos estágios supervisionados do curso.

Com todo este embasamento teórico e prático que o subprojeto propõe aos bolsistas, análise de aulas e da prática dos professores supervisores, o PIBID 
contribui para a compreensão de que a escolaé um processo dinâmico, em movimento, com contradições.

O subprojeto busca embasar os bolsistas teoricamente, e inserindo no ambiente escolar, para que possam compreender e intervir na escola.

Todas as respostas dosquestionários nos conduzem a pensar que 0 PIBID tem uma importância fundamental na formação acadêmica.

\section{CONSIDERAÇÕES FINAIS}

Tínhamos como problema para este estudo verificar quais as principais contribuições do programa para a formação dos acadêmicos, do curso de licenciatura em Educação Física da UNESC.

Compreendemos que o subprojeto de Educação Física da UNESC contribui com a qualificação profissional dos bolsistas, pois todos os bolsistas afirmam que a contribuição do PIBID é positiva, e apontam como justificativa o debate aprofundado dos textos, debates a atuação e o planejamento das aulas, que são extremamente importantes para a formação.

Todos estes estudos teórico-práticos são fundamentais, pois os bolsistas estudam na Universidade as bases teóricas e podem ter contato com a escola, não esperando somente pelo estágio, ou seja, constitui-se em um ambiente de formação inicial e continuada ao mesmo tempo.

Todo o embasamento teórico do subprojeto tem como objetivo compreender as bases teóricas das redes envolvidas que se reporta para perspectiva histórica cultural, sendo que esta perspectiva é a mesma da Proposta Curricular do município de Criciúma e do Estado de Santa Catarina.

A perspectiva histórico cultural é a base teórica de aprendizagem da proposta crítico-superada à, assim os textos que foram selecionados pelos coordenadores do subprojeto foi para compreensão dessa perspectiva e do objeto de estudo da educação física.

O tempo da graduação se torna insuficiente para realizar esse aprofundamento que fica possível com o subprojeto. A organização e sistematização neste sentido consegue contemplar os debates sobre a reflexão da práxis docente. Essa constatação é uma das questões mais destacadas pelos bolsistas. 
O subprojeto de Educação Física da UNESC articulado ao projeto politico pedagógico do curso consegue avançar na elaboração do pensamento teórico, colocando os bolsistas em atividade de estudos e com possibilidade para elaborar uma aula a partir de uma proposta que considera a base da proposta do município.

Deste modo, a partir do resultado da pesquisa compreendemos que estes quase dois anos do subprojeto do curso de Educação Física da UNESC, contribui com a formação dos bolsistas participantes, através da compreensão teórico-prática que a prática pedagógica requer.

Fica evidente que no estudo orientado pelos coordenadores, no debate, na observação, co-atuação e atuação nas escolas a visão de totalidade dos acadêmicos se amplia e a formação em educação física se qualifica. Nessa relação todos ganham em especial à escola pública.

\section{REFERÊNCIAS}

BRASIL. Portaria Normativa № 38, de 12 de dezembro de 2007. Dispõe sobre o Programa Institucional de Bolsa de Iniciação à Docência - PIBID. Diário Oficial da União, n. 239, seção 1, p. 39, 2007.

COLETIVO DE AUTORES. Metodologia do ensino da educação física. São Paulo: Cortez, 1992.

DAVIDOV. V.V. O que é a atividade de estudo. Revista Escola inicial, nº 7, 1999.

FRIZZO, Giovanni Felipe Ernst. Objeto de Estudo da Educação Física: as concepções materialistas e idealistas na produção do conhecimento. Motrivivência, Ano XXV, n 40, p. 192-206, jun. 2013.

NASCIMENTO, C. P. A atividade pedagógica da Educação Física: a proposição dos objetos de ensino e o desenvolvimento das atividades da cultura corporal. 2014. Tese (Doutorado em Educação) - Programa de Pós-Graduação em Educação, Faculdade de Educação da Universidade de São Paulo, São Paulo, 2014.

UNIVERSIDAde do eXtremo SUl CATARINENSE- UNeSC, Pibid Proposta Edital no 61/2013, 2013.

UNIVERSIDADE DO EXTREMO SUL CATARINENSE- UNESC, Projeto Pedagógicodo Curso de Educação Física. 2010.

VIGOTSKY, L. S. a formação social da mente. São Paulo: Martins Fontes, 2010. 